\title{
Applying Classic Code Switching to Bilingual Utterances of Bilingual Libyan Children in Oklahoma, USA
}

\author{
Azza Abugharsa \\ Oklahoma State University, Stillwater, USA
}

\begin{abstract}
Many studies have investigated the source of mixed utterances. Bilingual speakers switch languages for reasons such as lack of morphology required to complete the utterance monolingually, to accommodate to the topic, or to meet individual preferences, context, and other interlocutors' language(s). The focus in this paper is on classic code switching which requires full mastery of at least one of the languages involved in bilingual utterances. Data are collected from utterances of 16 Libyan children who live in USA, and who have learned English upon their arrival to USA at ages from two to five. It is argued that code switching can occur even when the speakers are not sufficiently fluent in either language. The children were interviewed by the researcher and the interviews were tape-recorded. The results show that although the children do not have full competence in the two languages (Arabic and English), they still produce bilingual utterances, and that although some of these utterances include Arabic as ML (Matrix Language), English seems to be the dominant language as it is the ML in the majority of bilingual utterances. It is concluded that switched utterances do not require full competence in either language in order to be produced.
\end{abstract}

Keywords: Libya, classic code switching, ML (Matrix Language)

\section{Introduction}

Many studies have investigated the source of mixed utterances; however, little attention was given to bilingual children's mixed utterances (Schmitt, 2000; Paradis, Nicoladis, \& Genesee, 2000; Pert \& Letts, 2006). CS (Code Switching) has been related to two major domains: sociopragmatic/discourse-related (WEI \& Milroy, 1995; Myers-Scotton \& Jake, 1995; Myers-Scotton, 1993) and structural (Joshi, 1985; Lowi, 2005). Bilingual speakers switch languages for a number of reasons: (1) to fill the morphosyntactic gap caused by lack of linguistic knowledge of one of the languages; (2) to accommodate to the topic, individual preferences, context, and other interlocutors' language(s). While Myers-Scotton (1993) stated that code switching is highly socially motivated, and that kind of motivation can "suppress other options over time” (p. 476). Myers-Scotton and Jake (1995) claimed that both languages are present at all times, and that bilingual utterances are the result of the difference of activation levels of both languages.

This paper investigates the premises underlying classic CS which states that bilingual speakers need to show full mastery of at least one of the languages involved in the bilingual utterances. Myers-Scotton (2006a) defined classic CS as:

Azza Abugharsa, Ph.D., English Department, Oklahoma State University. 
A type of CS that is made by speakers who must be proficient enough in the language structuring the clause so as to follow the well-formedness constraints of that language and may also be proficient in the other language although a high degree of proficiency is not very critical. (p. 242)

Classic CS is applied to the utterances of Arabic/English bilingual Libyan children who live in USA. It is argued that English is generally the matrix (dominant) language in the children's bilingual utterances, and that although the children do not have sufficient mastery of the languages involved (more explanation about the nature of this insufficient exposure to these languages is provided in the methodology section when discussing the research population), the morphosyntactic frame of their bilingual utterances is mostly English. Data are analyzed on the basis of the MLF (Matrix Language Frame model) proposed by Myers-Scotton (1993, 2002). This model includes two major submodels: the Abstract Level model and the 4-M model. The Abstract level model is used in this study to determine the dominant language in the subjects' bilingual utterances by focusing on the morpheme order and the nature of system morphemes used in these utterances, while the 4-M model provides a specific description of morphemes which are classified on the basis of their syntactic roles into content morphemes and system morphemes.

CS can be generally defined as the co-occurrence of items from two languages or more (or varieties of a language) within the same CP (complementizer phrase) "the highest unit assigned by lexical elements" or sentence (see Example 1).

Example (1) [TP Shawn said [CP [C that] [TP he decked the janitor]]] (Carnie, 2006, p. 73).

Bullock and Toribio (2010) defined CS as "the alternating use of two languages in the same stretch of discourse by a bilingual speaker” (p. 488); however, Toribio (2001) did not limit CS to two languages only. She referred to it as "the ability on the part of bilinguals to alternate between their linguistic codes in the same conversational event” (p. 204). In his definition of CS, MacSwan (2000) stated that CS is the use of two languages or more in the same $\mathrm{CP}$ by fluent bilinguals. Although he highlighted the fact that bilingualism is the use of two languages or more, he said that CS is a linguistic behavior that is limited to fluent bilinguals. In other words, he believed that CS occurs solely in the speech of bilinguals who have full mastery of all the languages involved. This contradicts the findings of research on CS and bilingualism that investigate the linguistic behavior of young bilinguals. Gonzalez-Vilbas and Lopez (2010), and Joshi (1982) limited CS practice to bilingual communities, and Joshi (1982, p. 145) argued that most research on CS is based on the sociolinguistic framework and discourse level; he also stated that intrasentential code-switching is part of the linguistic competence of the speakers and hearers of [bilingual] communities. Pert and Letts (2006) for example, conducted a research on preschool Mirpuri Pakistani children who live in U.K. They found that those children produced more switched utterances than monolingual utterances, and that their bilingual utterances were relatively longer. Muller (1998) on the other hand, investigated young bilingual's tendency to transfer parts of one language to the other in order to fill a gap in either language that caused ambiguity for the child due to insufficient knowledge of that language; such a process is said to be very important to the development of bilingual language. In addition, Paradis et al. (2000) investigated the structural constraints of French/English bilingual children's mixed utterances and compared it to the utterances of bilingual adults. The results showed that children produced more frequent violations to structural constraints as compared to the adults. Such results are said to be due to the children's insufficient (and unequal) linguistic input; however, they managed to produce bilingual utterances with their limited input they had at their disposal in the mental lexicon. 
Interestingly, some researchers defined CS as the alternation between two or more languages (Kim \& Rezaeian, 2009; Grosjean, 1982). CHUN (2010) stated that CS can occur by using more than two languages. However, CS can occur within one languages; Boussofara-Omar (2003) investigated Arabic diglossic switching (switching between Tunisian Arabic and Standard Arabic within a single CP). She used the MLF model to analyze the co-occurrence of system morphemes and the word order in CPs in which both varieties of Arabic occur. This study shows that CS can also occur in varieties of the same language; a characteristic that was not included in Garcia and Martinez (1981) definition of CS in which they stated that CS is "the altering use of more than one language by the bilingual” (p. 14). It can be said that providing a clear-cut definition of CS is not an easy task due to the dynamic factors that influence the process of CS and the nature of language(s) involved.

Researchers have related CS to two major domains: structural domain "which receives less attention" (Poplack, 1980), and sociopragmatic and discourse-related domain (Myers-Scotton, 1993; Myers-Scotton \& Jake, 1995; Lowi, 2005; Cummins, 1979; Pfaff, 1979; Pert \& Letts, 2006; WEI \& Milroy, 1995). These two domains are said to be interrelated; utterances produced by bilingual speakers are accommodated to different factors such as the topic, situation, individual preferences of speakers, and language(s) involved. This is supported by Gafaranga (2005) who stated that the social structure is invoked "[i]n order to account for the orderliness of language alternation, i.e., its structure... Language choice acts are said to 'index', to reflect, aspects of the social structure such as ethnicity, rights and obligations” (p. 282). Such social interactions are key factors in the analysis of CS. For instance, children in immigrant families are motivated to learn the language of the new society in order to get acquainted with the new environment. In order for young speakers to do so, they need to have access to the social, pragmatic, and linguistic rules and language behavior of the new society. According to Myers-Scotton (1993), CS is highly socially motivated. However, Myers-Scotton and Jake (1995) argued that all the languages are present all the time, and that the switched (mixed) utterances are in fact the result of unequal times of activation of these languages.

The focus in this paper is on the structural domain, i.e., the syntax of CS. Grammatical approaches to the study of CS phenomena have attracted the interest of many researchers who have conducted studies on the switched utterances and argued that switching can take place at and below sentential boundaries. Such cases are referred to as intersentential vs. intrasentential. Redouane (2005) summed up the distinction between intrasentential and intersential CS in that "[i]ntrasentential codeswitching used for switches within sentences, and intersentential codeswitching for switches between sentences” (p. 1921).

Intersentential CS is the production of an utterance in one language which is followed by another utterance in another language. In other words; every item maintains their internal structure in the switched utterance. Intersentential CS is defined by Appel and Muysken (1987) as the "alternation in a single discourse between two languages, where the switching occurs after a sentence in the first language has been completed and the next sentence starts with a new language” (p. 118) (see Example 2).

Example (2) I sometimes wait qui l'autre étudiant répondre. I sometimes wait until another student answer.

"I sometimes wait until another student answers".

In Example 2, the phrase "I sometimes wait" is in English, and the phrase "qui l'autre étudiant répondre" is in French. The speaker here produces one utterance in one language, and the other utterance in another language.

Intrasentential CS, on the other hand, includes the integration of the grammatical structures of morphemes 
in bilingual utterances. Bokamba (1988) referred to this kind of CS as code mixing; this could be, because intrasentential switching does not occur at clause boundaries, rather; it takes place within the clause in the bilingual utterances. This is supported by Pert and Letts (2006) who stated that "Intrasentential codeswitching occurs when lexical items or grammatical morphemes from two or more codes are incorporated into the same sentence, or more specifically, the same clause” (p. 351). Sentence 3 provides an example of intrasentential CS: It shows Arabic content morphemes inserted into English ML (see Example 3).

Example (3) Humma bring food and hajat like that.

They bring food and things like that.

Such utterances used to be viewed as deficiency in language skills and a violation of linguistic norms (Brice \& Anderson, 1999; Banerjee \& Guiberson, 2012; Guiberson et al, 2006; Kroll, 2008; Muto, 2010; Schiff-Myers, 1992). However, research has shown that intrasentential CS can be used to measure bilingual competence (Berk-Seligon, 1986), and that such bilingual utterances are not produced randomly; rather, they are syntactically and morphologically constrained. According to Bentahila and Davis (1983): "it is necessary to recognize a variety of syntactic constraints which restrict the environment where switching is possible” (p. 305).

As for bilingual children, a number of factors can affect the production of bilingual constituents and the variation of intersentential and intrasentential CS. According to Schmitt (2000), bilingual children tend to resort to CS due to insufficient knowledge of grammar required to express the communicative intentions desired, or due to vocabulary shortage of one of the languages involved, or due to the fact that their home language is different from that of the new community to which their families immigrate. In addition, Auer (2005, p. 404) stated that bilingual children tend to switch languages in order to establish a specific social identity that is called upon due to the current context and situation; and therefore, construct linguistic perceptions of social structures.

In the case of this current study, the subjects are young bilingual Libyan children who live in mid western university community. This study is different from other studies which focus on young bilinguals in that the families of these Libyan children are not immigrant families; they live in USA, because the parents (mostly the fathers) are graduate students, and they desire to go back to their home country (Libya) upon their graduation.

\section{Purpose of the Study}

In this paper, the data are analyzed on the basis of Matrix Language Frame model proposed by Myers-Scotton (1993, 2002). This model provides an understanding of the nature of Matrix Language vs. EL (Embedded Language) in order to find which language(s) constitute the morphosyntactic structure of bilingual CPs. In some situations, one language functions as the ML of the mixed CP; in other situations, however, more than one language functions as the source of the morphosyntactic structure of the bilingual CP. This unequal activation of the languages involved in the bilingual CP is a characteristic that distinguishes classic CS from composite CS (the participation of the two languages in constructing the morphosyntactic frame of the bilingual clause).

Classic code switching is applied to the data in this research. It is argued here that the criteria that characterize Classic CS does not necessarily match all kinds of bilingual utterances. Myers-Scotton (2002) stated that in classic CS, speakers are fully competent in at least one of the languages involved, but they have adequate mastery of the grammar of the other language(s) in order to make extensive use of it, i.e., "[i]n CS ... 
speakers have high proficiency in at least the language supplying the frame [ML]" (Myers-Scotton \& Jake, 2005). The second type is composite CS. In composite CS, the morphosyntactic frame includes all the languages involved, not just one, as in the case of classic code switching. In this case, the source of the structures produced is split between two languages (or more). Myers-Scotton (2002) provided Example 4 in which the English pattern (apple juice) was used instead of the Spanish pattern (juice of apple) by a bilingual Spanish/English Colombian child who lived in the USA (see Example 4).

$$
\begin{aligned}
& \text { Example (4) Mami, yo quiero manzana jugo } \\
& \text { Mommy, 1S/NO want/1S/PRES apple/FEM juice/MASC } \\
& \text { "Mommy, I want apple juice." }
\end{aligned}
$$

The argument in this paper is that the bilingual constituents produced by bilingual children, who do not have enough mastery of the languages involved, can have one language as the ML that structures the morphosyntactic frame of the bilingual constituent. It is argued that speakers may not have full access to the languages involved (as in the case of composite code switching) and yet one language can be the source of the structural frame of bilingual CPs. It is well-understood that the "fluency" prerequisite promoted by Myers-Scotton (2002) in her description of classic CS does not include bilingual children in that Myers-Scotton is surely aware of the fact that bilingual children have not yet fostered fluency in either of the languages involved and that it is only CS among bilingual adults that can be counted in classic CS. Accordingly, it is necessary to show how CS in this study actually happens by drawing attention to the difference between adult CS highlighted by Myers-Scotton and child CS. By doing so, it is desired to show exactly where Myers-Scotton's model, which depends on fluency in one language (usually the matrix one), fails to adequately account for the sorts of data encountered among children where that proviso is not the case.

In order to understand the nature and distinction between the two types of CS, a detailed explanation of the MLF model is required.

\section{The Matrix Language Frame}

The Matrix Language Frame proposed by Myers-Scotton (1993, p. 55), was primarily designed in order to analyze the structural configurations in classic CS. Muto (2010) stated that the MLF model "recognizes an asymmetric relation between the two languages involved in intrasentential CS” (p. 55). This means that the MLF model is used in many researches, because it offers a clear explanation for nearly all data of intrasentential CS in the literature (Myers-Scotton, 2002). Mayers-Scotton argued that the domain of the ML construct should be the CP, not the sentence, as the sentence can have more than one CP (see Example 5).

Example (5) [You can lead a horse to water] but [will it drink]? (Carnie, 2006, p. 207)

The MLF model contains two sub-models which were developed in order to offer an explanatory account of different types of contact data. This model provides an explanation of bilingual data and their empirical distributions by arguing that the competence aspects that seem to be restricted to bilingual data are in fact universal and can be applied to all kinds of language contact in which CS occurs. The argument in this paper contradicts this view as it is argued here that the MLF model does not necessarily apply to all kinds of CS, because languages involved in bilingual clauses can all be the dominant language in these kinds of clauses. In other words, the role of "dominant language" is not always restricted to one of the languages involved in the bilingual utterances.

In case of bilingual productions, the lexical rules activated are derived from all the languages involved; 
however, the languages constructing the bilingual CP are differently activated. Accordingly, bilingual CPs adhere to structural constraints provided by the MLF model which provides "an integrated, comprehensive set of constraints, rather than a single restriction on certain configurations” (Paradis et al, 2000, p. 248). As Myers-Scotton (2002) stated, the key characteristic of the MLF model is asymmetry; the dichotomy between the ML and the EL in the bilingual CP. Also, asymmetry plays an important role in determining the ML and the EL in the bilingual CP (Joshi, 1985). In this sense, the MLF model is based on two interrelated components: ML vs. EL, and content morphemes vs. system morphemes (Myers-Scotton, 1993). The latter will be explained later when the 4-M model is discussed.

\section{ML vs. EL}

The ML vs. EL distinction indicates that languages involved in the bilingual CP are not activated equally, i.e., they do not play identical roles; therefore, they do not undergo the same structural restrictions. The ML (the dominant, host, and recipient language) determines the language-specific lemmas which dominate the mixed utterances, in that it constructs the morphosyntactic frame of the bilingual $\mathrm{CP}$, and the EL elements are inserted into the ML frame. Such an unequal role of these languages results in specific structural constraints in the bilingual CP, and these constraints are used to determine which language is the ML. For example, in the MLF model, two principles are used to identify the ML in the bilingual CP: the System Morpheme Principle and the Morpheme Order Principle.

The System Morpheme Principle has to do with certain externally relevant system morphemes (late system morphemes) in the bilingual $\mathrm{CP}$ and that these morphemes must come from the ML. In other words, every system morpheme in a bilingual CP must come from the ML (see Example 6).

\section{Example (6) n-jeeb fi $\boldsymbol{l}$-marker $\mathbf{m t a a} \boldsymbol{l}$-saboora. I-bring in the-marker of the-board. \\ "I bring the board marker"}

Example 6 includes Arabic/English constituents. As noticed, Arabic is the ML, and the CP involves two system morphemes "l, mtaa, l" which are in Arabic, the ML.

The Morpheme Order Principle states that the surface morpheme order in the bilingual CP follows that of the ML. In other words, the surface morpheme order of the bilingual CP will be that of the ML in ML + EL constituents (see Example 7).

Example (7) I like to read this book jayed. (good)

Example 7 violates the grammatical structure of English (ML), because in English, adjectives precede the nouns they modify (Adj. + N). The phrase "book jayed" is under Arabic grammatical structure in which adjectives follow the nouns they modify ( $\mathrm{N}+$ Adj.). Hence, this sentence should follow the English morpheme order (Adj. + N) as English is the ML in this construction.

On the other hand, EL, which is involved in the CP that is dominated by ML, supplies lexical elements integrated into the ML frame. Those elements are inserted in the CP in the form of EL islands or bare forms: $E L$ islands are the well-formed constituents of EL which are included within the larger ML framed constituent. These islands are contained within the bilingual CPs and show structural dependency relationships, i.e., although they have their own internal grammatical structure, they basically depend on the larger ML in order to determine their placement in the CP (Myers-Scotton, 2006b). For example, in Example 8 French acts as the ML, and the English phrase “cute puppy” is the EL island (see Example 8). 


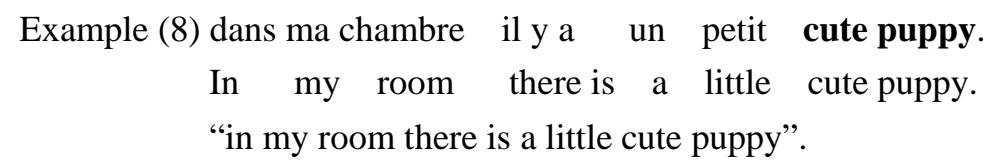

Bare forms, on the other hand, are the content morphemes that belong to EL which are not attached to ML morphemes; therefore, they are ill-formed constituents. In her study of Russian immigrant children in the USA, Schmitt (2000) stated that bilingual Russian/English children tend to produce bare content morphemes which come from the EL, and do not have the ML system morphemes attached to them. In Example 9, the EL English NP "park" is used without the Russian suffix (ML system morpheme) which is used to assign case in Russian (SR stands for Standard Russian) (see Example 9).

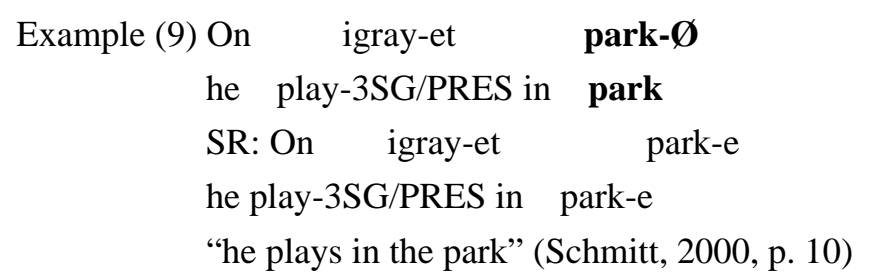

The 4-M model. This model deals with morpheme activation and the process by which these morphemes are accessed in the course of speech production. According to Fuller (2000) the 4-M model characterizes morphemes into four types (discussed below), and presents a theoretical explanation to both monolingual and bilingual language phenomena. The main argument in this model is based on the notion that "different lemmas underlying different types of morphemes become salient at different levels in speech production" (Boussofara-Omar, 2003, p. 35). This model involves 4 morphemes which are related to the process of production: the two major morpheme types are content morphemes and system morphemes, Boussofara-Omar (2003, p. 35) claimed that different lemmas underlying content and system morphemes become salient at different levels of speech production. System morphemes include two kinds: early system morphemes and late system morphemes. The latter involves late bridges and late outsiders. These morphemes are distinguished in three different ways: [+thematic role assigner/receiver] like content morphemes, [+conceptually activated] like content morphemes and early system morphemes, and [+structurally assigned] like bridges and outsiders (Myers-Scotton, 2008). Figure 1 illustrates these morphemes.

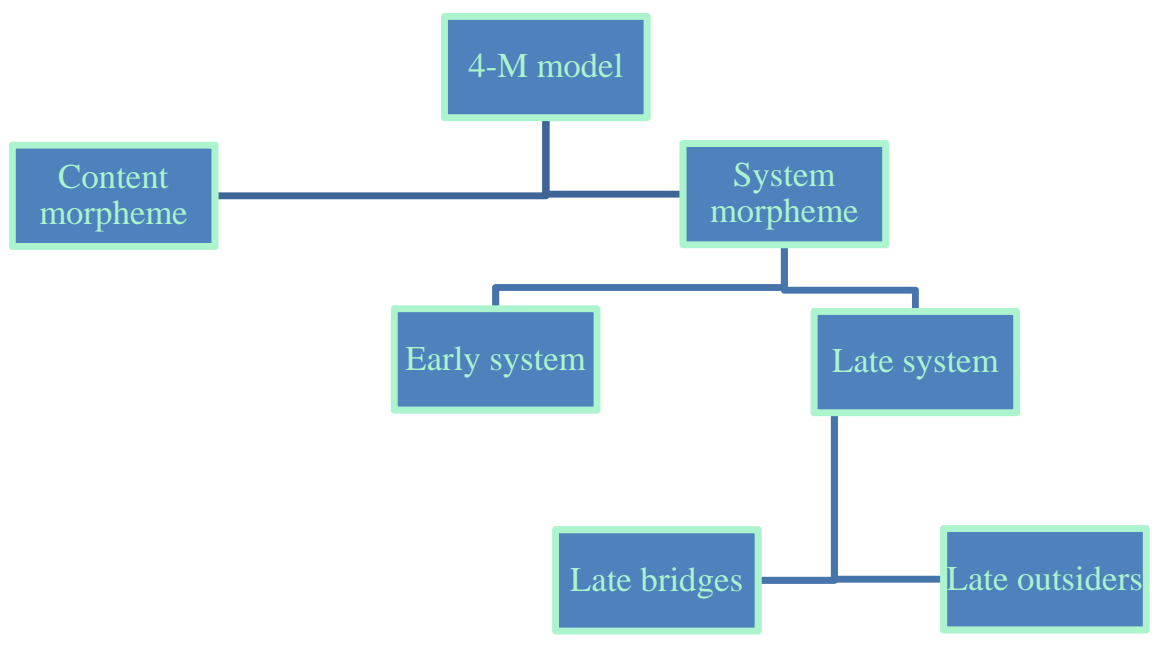

Figure 1. The 4-M model subdivisions. 
Content morphemes. Content morphemes are basically the words that carry meaning and whose lemmas are directly elected, such as nouns, verbs, adjectives, and adverbs. Myers-Scotton (2005) said that content morphemes "are the only ones directly activated by semantic and pragmatic features that match the speaker's pre-linguistic intentions” (p. 19). These morphemes hold the features [+thematic role assigner/receiver, -quantification] (Myers-Scotton, 2002) in that they are conceptually activated. Nouns receive thematic roles and most verbs and prepositions assign these roles. Therefore, one way to determine the ML in a given bilingual CP is by the most morphemes that bear content in the CP in one language. As far as quantification is concerned, quantifiers are always system morphemes, though not necessarily a feature of all system morphemes. An example of quantifiers is degree adverbs (e.g., too, very). Myers-Scotton (2002) used WEI's (1998) data from Chinese/English CS corpus in order to explain the feature of quantification. She said that once the quantifier is produced in EL, the phrase must end in EL too. Thus, it is not possible to say very nan "very difficult"; however, the constituent tai busy "too busy" is acceptable since busy is a content morpheme (Adjective). Myers-Scotton (2008) argued that the role of EL is largely limited to providing content morphemes to bilingual constituents as they (EL content morphemes) seem to express speakers' intentions more precisely than ML content morphemes. Also, she pointed out that EL nouns occur more frequently than EL verbs as the latter "have a more critical role than nouns; therefore, they come largely, or entirely, from the ML in most corpora... maintaining as much ML structure as possible makes the overall clausal structure as uniform as possible” (p. 28).

Content morphemes are directly and early activated. Moreover, they are conceptually activated, in that they are linked to speaker's intentions, which in turn, activate the semantic-pragmatic feature bundles underlying information expressed by content morphemes, i.e., speakers choice of specific content morphemes is based on the semantic and social factors represented in these morphemes. These bundles then point to lemmas in the mental lexicon (abstract lexical items) which underlie content morphemes that become salient at this point of language production process.

System morphemes. System morphemes, on the other hand, are [-thematic role assigner/receiver, + conceptual], because they do not express intention as content morphemes do, they (system morphemes) are assigned by content morphemes to refine their meaning at the lemma level. These morphemes are divided into two types: early system morphemes, and late system morphemes.

Early system morphemes depend on their heads for providing information regarding their form. Examples of early system morphemes are determiners and plural suffixes. According to Myers-Scotton (2002, p. 70) these morphemes are called early morphemes, because they are like content morphemes (conceptually-activated) in that "lemmas underlying them are salient at the level of mental lexicon". However, they are "indirectly-elected", i.e., they are activated by their heads (content morphemes) in order to add additional meaning to those content morphemes. Lemmas supporting system morphemes are activated when lemmas underlying content morphemes point to them. Therefore, the form and appearance of system morphemes depend on lemmas that select them, i.e., they depend on the maximal projection of the content morpheme that activates them. For example, plural markers (e.g., s In English) are considered early system morphemes as they are elected by the noun (content morpheme) to which they are attached (Fuller, 2000, p. 48). Similarly, grammatical features encoded in past participle markers (irregular forms) are also system morphemes in that their features are stored within the verb stem on which their form depends.

As for late system morphemes, they are the grammatical markers used to satisfy the requirements of the 
grammatical structure of EL. These morphemes are called late system morphemes, because they do not become salient until content morphemes and early system morphemes (where applicable) send directions to the formulator which is defined by Amuzu (2005) as “a kind of 'control center' in actual online production” (p. 133) to activate larger structures of constituents. In other words, late system morphemes are activated when information from content morpheme lemmas and early system morphemes attached to them in the mental lexicon are sent to the formulator. Bridges are said to be dependent on information derived from content morphemes other than those within their immediate maximal projection. As Myers-Scotton (2006b) put it, “[b]ridges satisfy language-specific requirements that make a specific constituent type well-formed” (p. 208). Therefore, late system morphemes are structurally-assigned as they become salient when their lemmas are activated at the level of the formulator to which language-specific directions are sent. There are two types of late morphemes: late bridges [-conceptually activated/-outsiders of the head] which integrate morphemes into larger constituents and connect different content morphemes, examples of bridge late morphemes are "of" and "s" which link nouns (content morphemes) within a noun phrase. Also, bridges come mostly from the ML, because they are not available for transfer in situations of linguistic contact the same way content morphemes and early system morphemes are (Myers-Scotton, 2008).

The second kind of late morphemes is called "outsiders"; their form depends on grammatical information that comes from an element outside their immediate CP. An example of these morphemes is morphemes marking subject or object verb- agreement (English 3rd Person singular s, e.g., he eats), while agreement is assigned to the verb; it is dependent on the subject. Another example is the English quantifier "any" which is coindexed with negation outside the NP in which they occur (Fuller, 2000). Myers-Scotton (2002, p. 70) explained that these morphemes are called late morphemes, because "lemmas underlying them are not fully salient in language production until the level of the formulator where larger constituents are assembled”.

\section{Content Morphemes vs. System Morphemes}

The second component on which MLF model is based has to do with the distinction between content morphemes and system morphemes. This distinction is derived from the way these morphemes pattern in accordance with frame building properties (Myers-Scotton, 2002). In intrasentential CS, lexical categories such as Nouns (N.), Adverbs (Adv.), Adjectives (Adj.), Prepositions (P.), and most verbs (V.) are prototypical content morphemes; some of which receive thematic roles (such as nouns) others assign thematic roles (such as verbs and some prepositions) in order to constitute the predicate-argument structure. While nouns and adjectives receive thematic roles, verbs and some prepositions assign thematic roles. System morphemes can be free or bound; examples of system morphemes involve auxiliary verbs, articles, determiners, verb, and noun infections copula, and negative operators. Consequently, content morphemes are recognized as [+thematic assigner/receiver] and system morphemes are defined by the feature [-thematic assigner/receiver].

The abstract level model. The second sub-model underlying the MLF model is the Abstract Level Model. This model is proposed by Myers-Scotton and Jake (1995) who stated that the model is useful in two ways: First, it provides a detailed explanation regarding the "sufficient congruence" in CS in that specific constructions are possible for specific pairs in bilingual CPs, i.e., EL morphemes are checked for "sufficient congruence" with their ML counterparts; this checking takes place in the mental lexicon at the lemma level (Myers-Scotton, 2002, p. 20). Second, it explains the nature of the morphosyntactic frame in bilingual structures in linguistic contacts other than classic CS, e.g., bilingual utterances in which elements (of all the 
languages involved) are combined in the bilingual CP “composite CS”.

The major premise underlying this model is based on the nature of lemmas in the mental lexicon. It is argued that all lemmas involve three levels of abstract lexical structure which exist in all lexical items; these levels include grammatical information required for surface realization of a lexical entry. These levels are: Lexical-conceptual structure (semantic/pragmatic feature bundles between conceptualizer and mental lexicon), Predicate-argument structure (relation among content morphemes "thematic structure"), and Morphological realization patterns (morpheme order and agreement morphology).

The lexical-conceptual structure. This level is very close to speakers' pre-verbal intentions, which operate language-specific semantic/pragmatic feature bundles. These bundles are mapped into entries in the mental lexicon as lexical-conceptual structure (Mayers-Scotton, 2002, p. 19) which are sent out as information to the formulator at the functional level.

Predicate-argument structure. The focus in this level is on the way content morphemes are structurally assigned in a given language. This level deals with thematic role assigners (e.g., P., V.) and how they are mapped to grammatical relations in phrase-structure units.

Morphological realization pattern. This level deals with how grammatical relations (constituent order onto which thematic roles are mapped based on well-formedness constraints) are identified in surface configurations. These three levels of abstract grammatical structure are accessed independently from each other and viewed individually depending on the nature of the languages involved. Figure 2 illustrates these three levels.

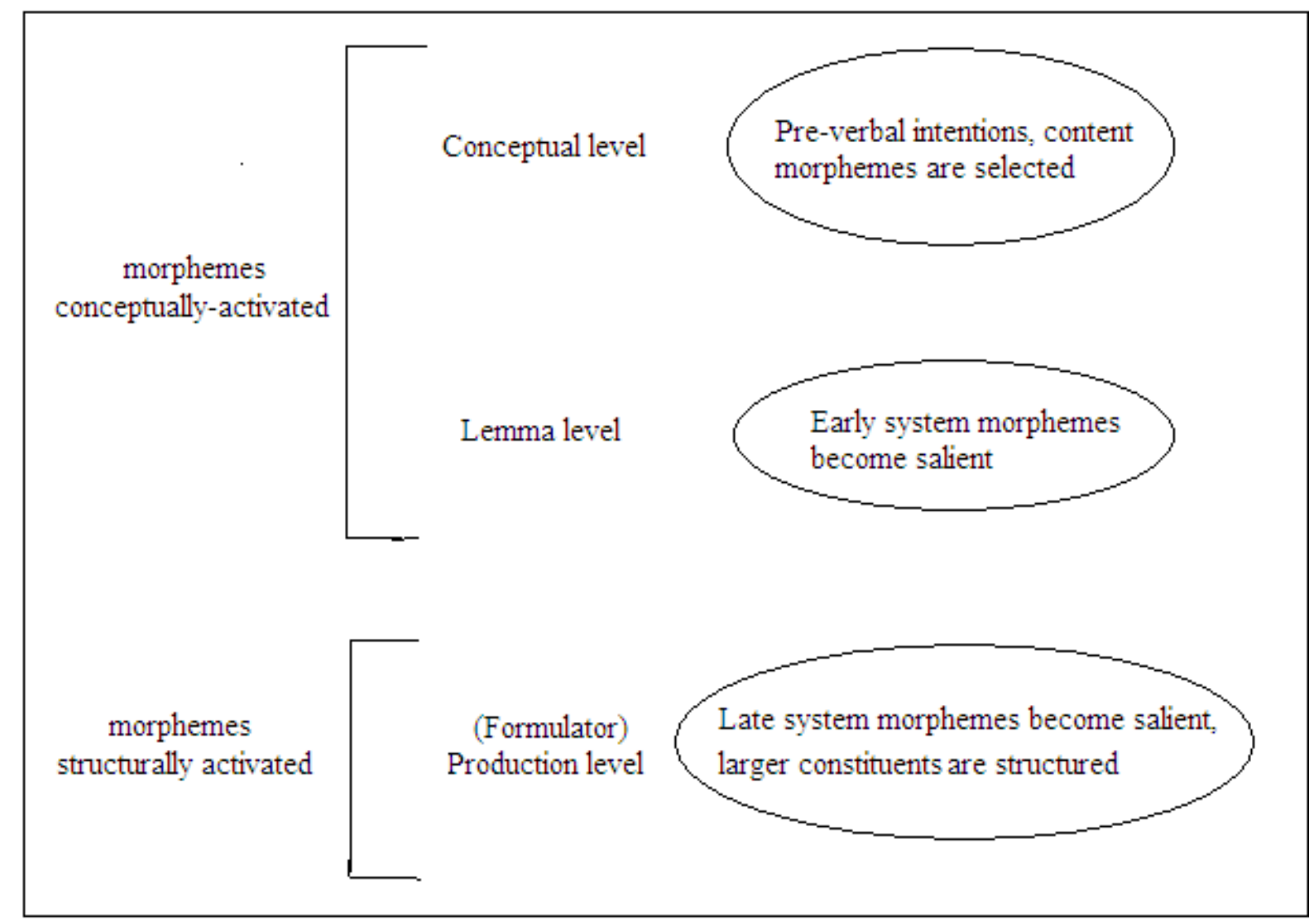

Figure 2. The three levels of Abstract Lexical Structure. 
In this paper, the focus is on one kind of CS discussed by Myers-Scotton (2002); classic CS. Myers-Scotton stated that this kind of CS depends on mastery level of languages involved, with one language being the ML all the time as it is the language the speakers have full mastery of. It is well-understood that Myers-Scotton has in mind the fact that bilingual children naturally do not have sufficient proficiency in any of the languages involved as they are still in the process of developing their language proficiency; nonetheless, this fact should have been included in Myers-Scotton's description of classic CS in order to signal it out as an exception and subsequently prevent overgeneralizing the concept on all aspects of CS. Classic CS is applied to the bilingual utterances of Arabic/English bilingual Libyan children who live in the USA. It is argued here that CS can occur in the bilingual utterances of those bilingual children who still do not have sufficient competence in any of the languages used in their bilingual CPs (bare forms termed "ill-formed constituents" are used as evidence of this incompetence). Also, it is argued that although both languages can be the ML in different bilingual CPs, English is mostly used as the ML in the majority of utterances.

\section{Methodology}

This paper investigates the syntactic features of the speech of 16 (ages 5-11) Bilingual Libyan children who live in mid-west university community. The participants (nine females and seven males) speak Libyan Arabic (a variety of standard Arabic) and have only learned English when they came to USA at the age of two and above. They lived the first two years (or more) of their lives in Libya, and only learned English when they came to USA. The children included in the study originally came to Stillwater, because their fathers are graduate students at the University. Table 1 illustrates age distribution of the participants.

Table 1

Age Distribution of Participants

\begin{tabular}{|c|c|c|c|c|c|}
\hline No. & Name & Gender & Age of arrival in the USA & Period of residency in USA by year & Current age \\
\hline 1 & $\mathrm{Ab}$ & M & 6 & 2 & 8 \\
\hline 2 & Ad & M & 2 & 4 & 6 \\
\hline 3 & $\mathrm{Al}$ & $\mathrm{F}$ & 5 & 5 & 10 \\
\hline 4 & Ay & F & 3 & 4 & 7 \\
\hline 5 & $\mathrm{Ba}$ & M & 4 & 4 & 8 \\
\hline 6 & $\mathrm{Fa}$ & $\mathrm{F}$ & 6 & 5 & 11 \\
\hline 7 & На & M & 4 & 5 & 9 \\
\hline 8 & Ky & $\mathrm{F}$ & 2 & 3 & 5 \\
\hline 9 & Md & M & 7 & 2 & 9 \\
\hline 10 & $\mathrm{Ma}$ & $\mathrm{M}$ & 2 & 5 & 6 \\
\hline 11 & $\mathrm{Mr}$ & F & 7 & 4 & 11 \\
\hline 12 & My & F & 2 & 3 & 5 \\
\hline 13 & $\mathrm{Na}$ & $\mathrm{M}$ & 6 & 4 & 10 \\
\hline 14 & $\mathrm{Ra}$ & F & 2 & 5 & 6 \\
\hline 15 & $\mathrm{Re}$ & F & 3 & 4 & 7 \\
\hline 16 & Sa & F & 2 & 4 & 6 \\
\hline
\end{tabular}

All the children go to Elementary school (in which they speak English only) Monday to Friday from 8:30 a.m. till 3:30 p.m., and then they go to the Family Center, in which they also speak English only from 4:00 p.m. 
until 6:00 p.m.. Every Sunday they go to Arabic School at the mosque (where they speak mostly Arabic) from 11 a.m. until 4:00 p.m. to learn Modern Standard Arabic. By asking the parents, it is known that the language mostly spoken at home is Arabic, with English being used as well, only less frequently. Those families intend to go back to their home country upon the fathers' graduation from the University.

\section{Data Collection}

This paper focuses on CS (from and into Libyan Arabic and English) performed by those bilingual Libyan children in order to elicit more data regarding the grammatical structure of their bilingual utterances on the basis of ML structure. The children were interviewed separately by the researcher; each interview session was audio-taped and lasted from 6 to 8 minutes. The researcher discussed topics with the participants related to their everyday life, events, and activities (e.g., activities at school with friends and at home with the family).

\section{Analysis and Discussion}

The participants were interviewed by having open conversations in which English and Libyan Arabic were used. The researcher asked questions in both English and Arabic, and the children answered by using the two languages as well, and the frequency of using either language as the ML was varied. Data analysis is based on two criteria: the first one is English/Arabic islands vs. English/Arabic bare forms which are used as evidence of the subjects' insufficient linguistic competence in the two languages. It is claimed that bare forms are used less frequently than EL islands, because participants tend to rely on both languages to fill in the gaps in their bilingual utterances due to their lack of appropriate linguistic constructions in either language. The second criterion is English ML vs. Arabic ML frequency of occurrence which reflects the major ML used in most of the subject's bilingual utterances. In other words, although each one of the two languages does occur as an ML in some utterances, one of these languages (English) represents the general dominant ML in the bilingual utterances as a whole.

\section{English/Arabic Islands vs. English/Arabic Bare Forms}

In order to discuss the first criteria more clearly, we need to compare the frequent occurrence of EL islands to bare forms in both languages. Table 2 shows the number and percentage of English/Arabic EL islands vs. English/Arabic bare forms as compared to the total number of all the CS utterances.

Table 2

Numbers and Percentages of Occurrence Frequency of English/Arabic Islands as Compared to English/Arabic Bare Forms

\begin{tabular}{|c|c|c|c|c|c|}
\hline & \multicolumn{2}{|c|}{ English/Arabic islands } & \multicolumn{2}{|c|}{ English/Arabic bare forms } & \multirow[t]{2}{*}{$P$-value } \\
\hline & No. & (\%) & No. & (\%) & \\
\hline \multirow[t]{2}{*}{ Total } & 101 & 53 & 91 & 47 & 0.5161 \\
\hline & \multicolumn{3}{|c|}{$192 / 100 \%$} & & \\
\hline
\end{tabular}

As Table 2 shows, the number of English/Arabic islands is larger than that of English/Arabic bare forms; however, the difference is not very large. Because the $p$-value is greater than the usual alpha $=0.05$ level, it is concluded that there is no significant difference between the two groups.

Although islands are used more frequently than bare forms, this does not mean that the use of bare forms is minimal; as the table shows, $47 \%$ of the subjects' CS utterances are bare forms. This is a rather high 
percentage and quite predictable taking into consideration the fact that the subjects are children under 11and are still developing linguistic competence in the two languages.

Bare forms occur in different cases such as: when ML system morphemes are not attached to EL content morphemes in the bilingual CP, when EL system morphemes are used instead, or when no system morphemes are used in bilingual CPs in which such morphemes are required. Sentences in $(10,11,12$, and 13) are given as examples of these cases (see Example 10).

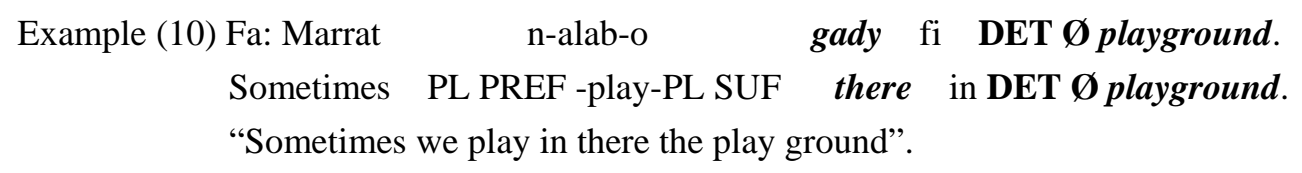

Example 10 shows the lack of what Myers-Scotton (2002) refers to as determiner complex in which she states that when a demonstrative is used in an Arabic sentence or phrase, it is followed by a determiner and a noun (e.g., gady + DET + N). The phrase "gady fi playground" does not include the determiner (al "the") required for the phrase to satisfy the determiner complex rule. Therefore, the phrase "gady fi playground" is ill-formed; it is a bare form in the bilingual CP. As Mayers-Scotton argued that Arabic NPs should be preceded by the definite article "the", Example 11 includes two ill-formed English NPs (Friday, juma'a) in a bilingual CP in which Arabic is the ML and thus the Arabic definite article "al" (being a system morpheme) is supposed to precede the English NPs. The same analysis can be applied to Example 12 in which the Arabic NP "dars" is not preceded by the English definite article "the" (as English is the ML in this example and system morphemes in bilingual CPs come from the ML) (see Examples 11-12).

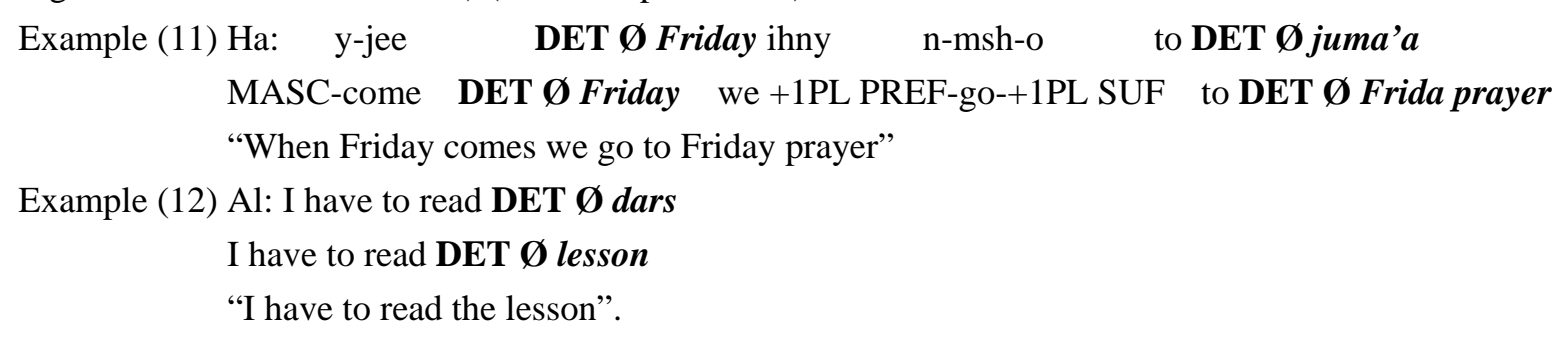

Other examples of bare forms are in Example 13a and Example 13b which show the use of inappropriate system morphemes as definite articles. Example 12a shows how the English definite article "the" is used in a bilingual CP in which English is the EL and Arabic is the ML. Similarly, the bilingual CP in Example 13b includes the Arabic definite article "al” with Arabic being the EL and English being the ML (see Examples 13a-13b).

Example (13a) Ba: Nehna kona fi ${ }^{*}$ the jame’a

We were in " the mosque

"We were in the mosque".

Example (13b) Ba: On Sunday I go to *al-Arabic school.

On Sunday I go to the Arabic school.

"On Sunday I go to the Arabic school".

As discussed earlier, system morphemes include examples such as plural suffixes, subject-verb agreement, and possessive "of". Example 14 illustrates the use of the English plural suffix "s" (in NP suras) in a bilingual CP in which Arabic is the ML. As for Example 15, the VP (n-read) does not include the Arabic plural suffix that needs to be attached to the main verb (PL PREF + VP + PL SUF) when the subject is the 1st person plural 
(we). Accordingly, the VP (n-read) is an English bare form in the bilingual CP. According to MLF model, possessive "of" is a system morpheme, so it should be used in the language that represents the ML in the bilingual CP. The possessive "of" in Example 16 is in English which is the EL not the ML in that CP, as a result; the phrase "of Arabic words" is a bare form (see Examples 14-16).

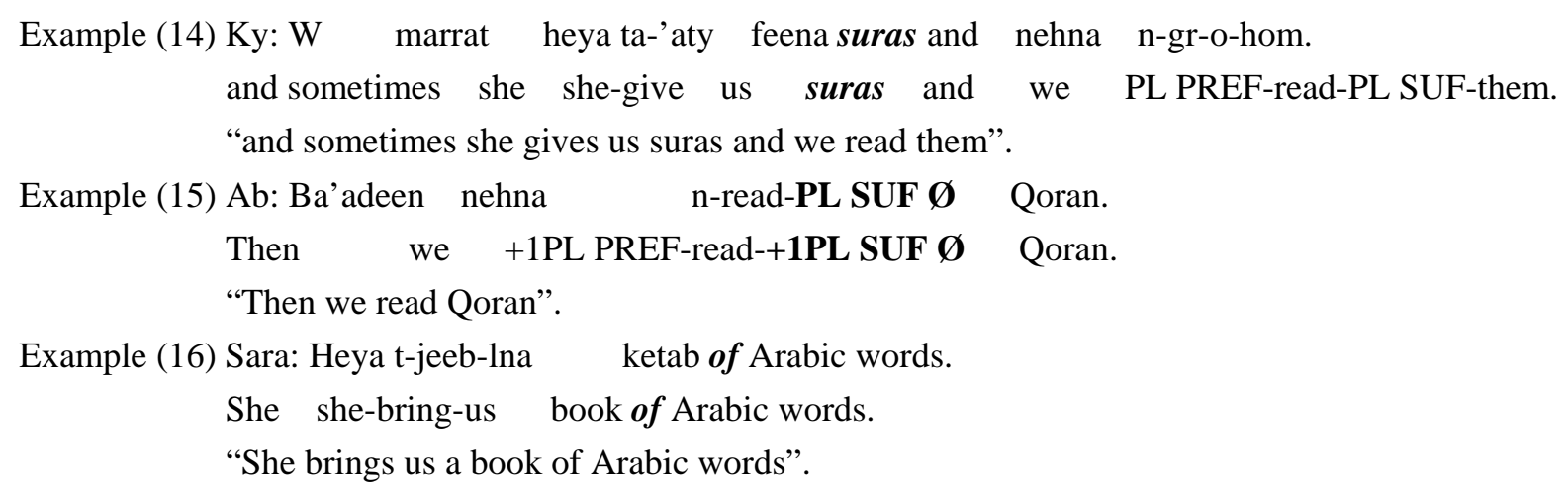

As we can see, bare forms of several kinds occur frequently in the subjects' bilingual utterances with a percentage of $47 \%$ of overall the CS utterances. Moreover, the frequency of using English bare forms vs. Arabic bare forms is varied, with English bare forms occur significantly more than Arabic ones. Table 3 shows the number and percentage of using these bare forms.

Table 3

Number and Percentage of English Bare Forms vs. Arabic Bare Forms

\begin{tabular}{lllcl}
\hline \multicolumn{3}{c}{ English bare forms } & Arabic bare forms & $P$-value \\
\hline No. & $(\%)$ & No. & $(\%)$ & \\
62 & 68 & 29 & 32 & 0.0007053 \\
\hline Total: $91 / 100 \%$ & & & & \\
\hline
\end{tabular}

Table 3 shows that English bare forms are used more frequently than Arabic bare forms. Because the p-value is less than the usual alpha $=0.05$ level, it is concluded that there is a significant difference between the two groups. In other words, English Bare forms occur more often than Arabic Bare forms.

In general, the frequent use of these ill-forms indicates that the subjects do not have full mastery of the two languages required to produce well-formed bilingual utterances. The subjects' restoration to English bare forms over Arabic ones can be related to the fact that they generally speak English more than Arabic in their everyday lives and activities. Arabic is spoken (together with English) at home and at the Sunday Arabic school, whereas English is spoken mostly all the time and everywhere, i.e., the subjects are exposed to English more than Arabic and tend to insert English bare forms and islands into Arabic phrases in order to fill the morphological and syntactic gaps encountered in Arabic utterances.

The frequency of the occurrence of English bare forms vs. Arabic bare forms differs on the basis of the subject's length of residency in the United States. The more the subjects stayed in the United States the more they got exposed to English in addition to Arabic, and subsequently the less bare forms they use. The reason is that bare forms are ill forms that result from inadequate competence of the language(s) to which the individual is exposed, and the more the individual uses that language the less bare forms are likely to occur. Table 4 shows how the occurrence of bare forms decreases as the subjects' length of residency in the United States increases. 
Table 4

The Inverse Proportion Between Subjects' Length of Residency in USA and Their Frequent Use of Bare Forms

\begin{tabular}{|c|c|c|c|c|c|}
\hline \multirow{2}{*}{ No. } & \multirow{2}{*}{ Name } & \multirow{2}{*}{ Length of residency in USA by year } & \multirow{2}{*}{ Current age } & \multicolumn{2}{|c|}{ Bare forms } \\
\hline & & & & English & Arabic \\
\hline 1 & $\mathrm{Ab}$ & 2 & 8 & 10 & 4 \\
\hline 2 & Md & 2 & 9 & 9 & 5 \\
\hline 3 & My & 3 & 5 & 8 & 5 \\
\hline 4 & Ky & 3 & 5 & 7 & 3 \\
\hline 5 & Ad & 4 & 6 & 6 & 3 \\
\hline 6 & Ay & 4 & 7 & 4 & 2 \\
\hline 7 & $\mathrm{Ba}$ & 4 & 8 & 3 & - \\
\hline 8 & Ma & 5 & 6 & 3 & 2 \\
\hline 9 & $\mathrm{Mr}$ & 4 & 11 & - & - \\
\hline 10 & $\mathrm{Na}$ & 4 & 10 & - & 1 \\
\hline 11 & $\mathrm{Ra}$ & 5 & 6 & 5 & 1 \\
\hline 12 & $\mathrm{Re}$ & 4 & 7 & 2 & - \\
\hline 13 & Sa & 4 & 6 & 2 & 1 \\
\hline 14 & На & 5 & 9 & 2 & 2 \\
\hline 15 & $\mathrm{Fa}$ & 5 & 11 & 1 & - \\
\hline 16 & $\mathrm{Al}$ & 5 & 10 & - & - \\
\hline
\end{tabular}

Also noticed in Table 4 the fact that English bare forms are used more frequently than Arabic bare forms, and again the more the subjects have stayed in the States, the less these English bare forms are used. However, they generally occur more than Arabic ones; a fact that indicates the dominance of English over Arabic in the subjects' bilingual utterances. Figure 3 represents these data, with the names of participants listed from left to right in the order of the length of residency in USA (the participants at the right have stayed longer time in USA).

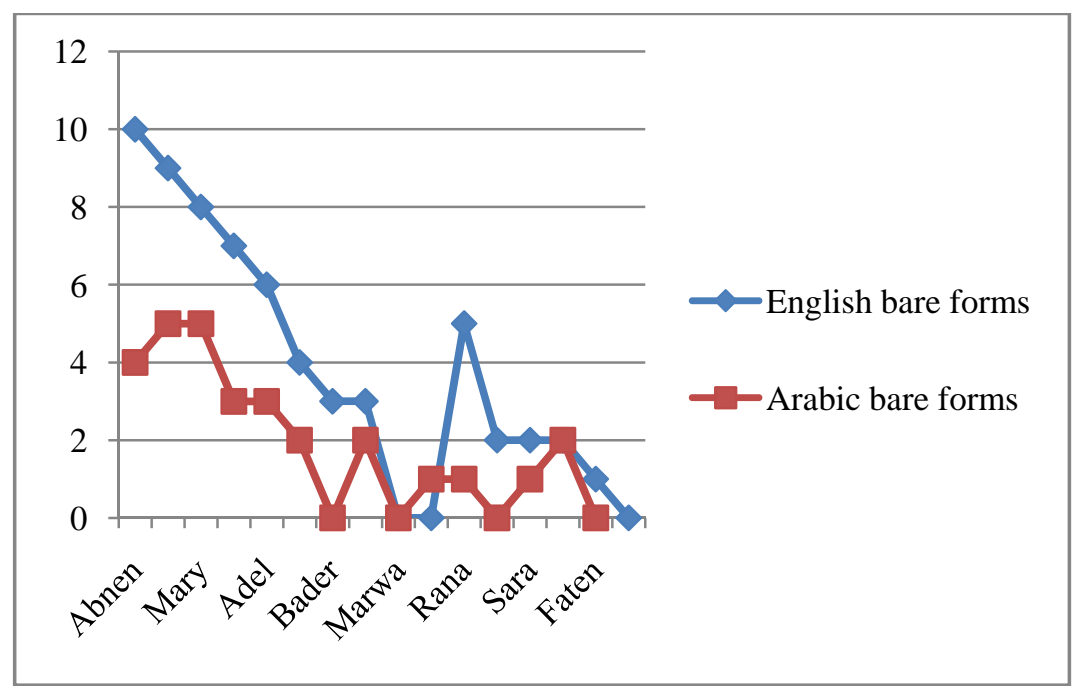

Figure 3. The decreasing rate of bare forms as the length of residency in USA increases.

\section{English Islands vs. Arabic Islands}

Islands are used more often than bare forms in the research data. As a matter of fact, islands may be considered a continuation of bare forms, i.e., when linguistic competence develops, less bare forms are used 
and more islands are likely to appear. As a result, the children who have stayed longer in the USA show more tendencies to use islands than those who have spent less time in this country. Table 5 supports this argument.

Table 5

The Inverse Proportion Between Subjects' Length of Residency in USA and Their Frequent Use of English and Arabic Islands

\begin{tabular}{|c|c|c|c|c|c|}
\hline \multirow{2}{*}{ No. } & \multirow{2}{*}{ Name } & \multirow{2}{*}{ Length of residency in USA by year } & \multirow{2}{*}{ Current age } & \multicolumn{2}{|c|}{ Islands } \\
\hline & & & & English & Arabic \\
\hline 1 & $\mathrm{Ab}$ & 2 & 8 & 3 & 2 \\
\hline 2 & Md & 2 & 9 & 4 & 3 \\
\hline 3 & My & 3 & 5 & 3 & - \\
\hline 4 & $\mathrm{Ky}$ & 3 & 5 & 4 & 2 \\
\hline 5 & Ad & 4 & 6 & 4 & 1 \\
\hline 6 & Ay & 4 & 7 & 5 & - \\
\hline 7 & $\mathrm{Ba}$ & 4 & 8 & 5 & - \\
\hline 8 & Ма & 5 & 6 & 3 & 2 \\
\hline 9 & $\mathrm{Mr}$ & 4 & 11 & 4 & 1 \\
\hline 10 & $\mathrm{Na}$ & 4 & 10 & 5 & 2 \\
\hline 11 & $\mathrm{Ra}$ & 5 & 6 & 6 & 1 \\
\hline 12 & $\mathrm{Re}$ & 4 & 7 & 6 & 2 \\
\hline 13 & Sa & 4 & 6 & 7 & 1 \\
\hline 14 & На & 5 & 9 & 7 & - \\
\hline 15 & $\mathrm{Fa}$ & 5 & 11 & 9 & 1 \\
\hline 16 & $\mathrm{Al}$ & 5 & 10 & 8 & - \\
\hline
\end{tabular}

Table 5 shows how the use of English/Arabic islands increases with the extended lengths of residency in Oklahoma. The subjects are exposed to both English and Arabic; however, this exposition is not equal. As understood from asking their parents, the subjects speak Arabic and English at home and at the Sunday Arabic School, and speak English only elsewhere. In other words, there are more chances in which the children use English islands more than Arabic islands as indicated in Table 5; thus, English acts as the overall dominant language to which the children resort in order to make up for any linguistic gaps encountered when they speak in Arabic. Figure 4 illustrates the relationship between length of residency in the USA and the frequency of using islands in the subject's bilingual utterances. The names of participants listed from left to right in the order of the length of residency in USA (the participants at the right have stayed longer time in USA).

As demonstrated in Figure 4, English islands are used remarkably more than Arabic islands. This means that English is the subjects' dominant language even though a number of bilingual CPs in which Arabic is the ML appear. It is argued that the subjects, being children who are still going through the process of language acquisition, resort to English in order to fill linguistic gaps in Arabic CPs; such gaps occur in the subjects' utterances due to the unequal and insufficient competence of Arabic as compared to English. Example 16, for instance, shows how the child chooses to say "marker" in English as an "avoidance" strategy instead of using the Arabic word either, because the child does not know it or, because he/she is not sure how to say it correctly (these clues were suggested by the parents when they were asked by the researcher about their children's choices of languages when they speak bilingually). Similar analysis can be applied to Examples 17-18; in 
Example 17 the subject uses the English word "room" instead of its Arabic equivalent which is not known by the child. As for Example 18, the subject uses the words "donuts and coffee" as English EL islands in a CP in which Arabic is the ML. Notice that. As Kassabgy et al. (2004, p. 62) stated, the Arabic definite article "al" is attached to NPs whose heads are either singular or plural. Accordingly in Example (18), the Arabic definite article "al" is attached to the English word "donuts" which is plural unlike the singular words "marker and room" in the previous two examples (see Examples 16-18).

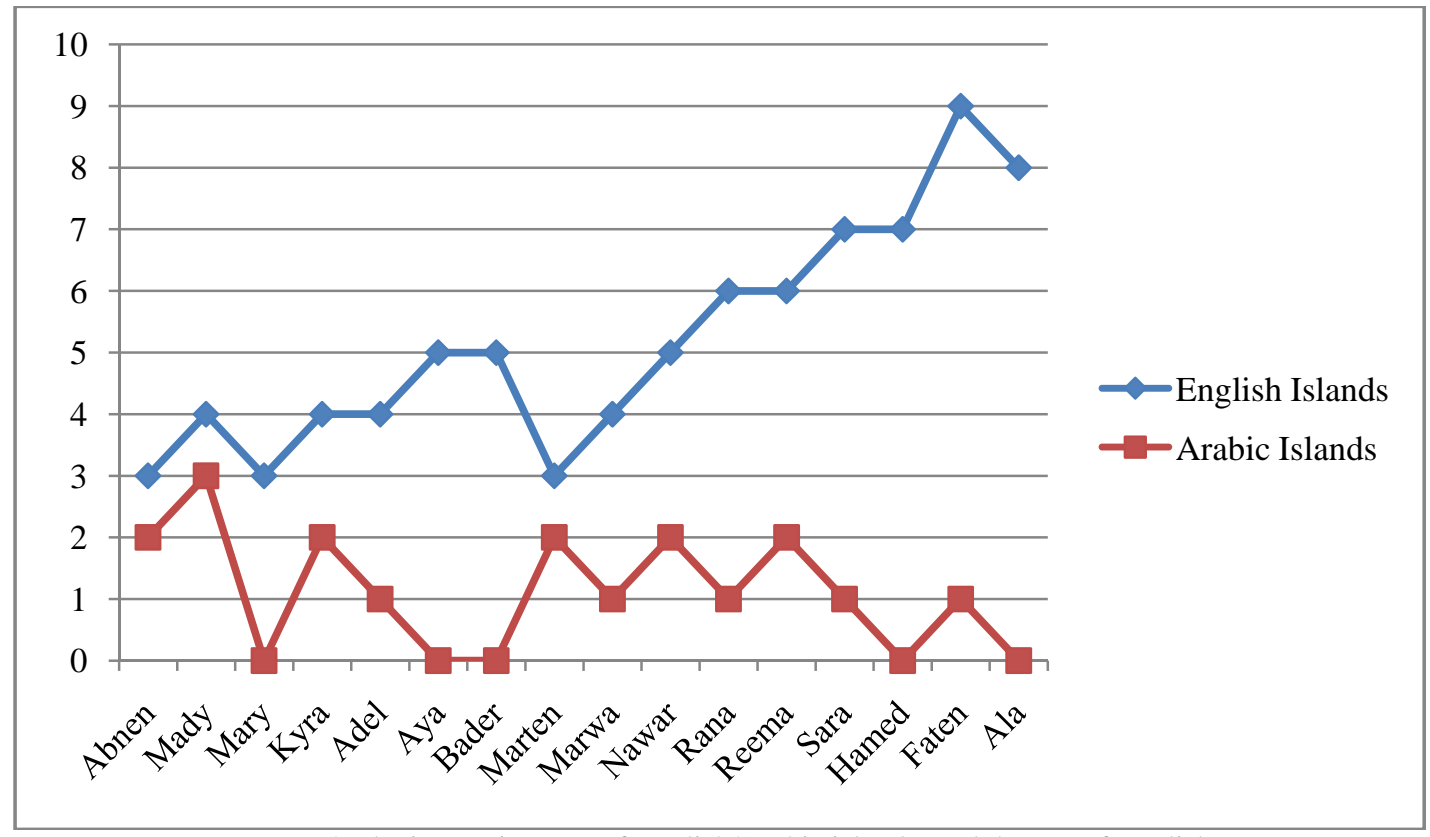

Figure 4. The increasing rate of English/Arabic islands, and the use of English islands more than Arabic ones as the length of residency in USA increases.

Example (16) Mr: n-jeeb fi al-marker mta'a a-sabbora.

I-bring in the-marker of the-board.

"I bring the marker of the board".

Example (17) Al: Mama t-ga’amez wa ana n-emshe dakhel al-room besh n-ala’ab Mommy she-sit and I I-go inside the-room to I-play

"Mommy sits and I go inside the room to play".

Example (18) Mr: N-med-o l-l-nas al-donuts wa al-coffee wa kol shai We-give-PLU SUF to-the-people the-donuts and the-coffee and every thing.

"We give the people donuts and coffee and everything".

Examples 16-18 show that English is used as an EL in ML Arabic bilingual CPs. The Arabic definite article "al" is a system bound morpheme which is attached to English EL NPs which makes Arabic the ML based on the characteristics of ML in the MLF model. The English NPs in Example 19 school and FRC (Family Resource Center) are used as EL islands to which Arabic preposition (l "to") and the Arabic definite article ( $a l$ "the") are used. We understand that ML Arabic system morphemes have to be attached to EL English NPs in English/Arabic bilingual CPs. As a result, the use of EL English morphemes in an ML Arabic CP without Arabic system morphemes attached to them would be considered more of EL English bare forms than EL English islands as shown in Example 20. 


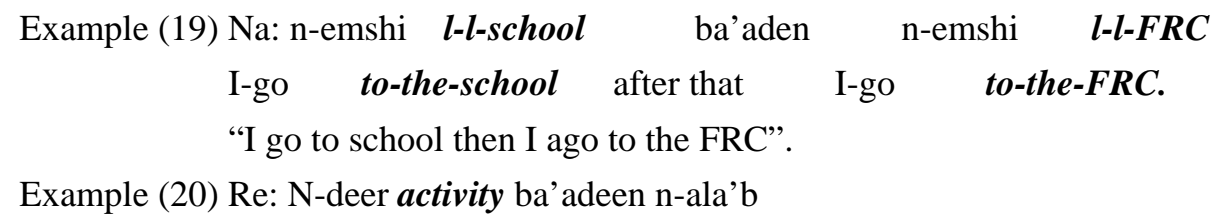

I-do activity then I-play.

"I do an activity then I play".

Interestingly, phrases which are used as EL islands also occur in the subjects' switched utterances. In Example 21 for example, the English DP "two weeks ago" is an EL island, because it does not violate MLF model principles which state that all system morphemes and morphosyntactic order of the bilingual CP must be in the ML. Arabic is the ML in Example 21 as it is the language that constructs the morphosyntactic frame of the utterance. Similarly, Example 22 includes an English VP "bring food" which is an EL island in an Arabic ML bilingual CP in which Arabic builds the morphosyntactic frame of the utterance. Likewise, the English AdvP "sometimes" in Example 23 is an EL island in the bilingual CP. The grammatical structure in Example 23 is in Arabic, the VP (na'alb-o "we play") includes 1st person plural pronoun "n-" plus the main verb and they are both in Arabic, the NP (barra "outside") is also in Arabic; accordingly, Arabic is the ML that plays the larger structural role in this bilingual CP (see Examples 21-23).

Example (21) Ha: heya dara-t-h two weeks ago.

She did-she-it two weeks ago.

"She did it two weeks ago".

Example (22) Fa: Homma bring food wa hajat zay hadi.

They bring food and things like that.

"They bring food and things like that".

Example (23) Sa: Sometimes ihney n-a'alab-o barra.

Sometimes we we-play-PL SUF outside.

"Sometimes we play outside".

In addition to English ELs, Arabic ELs are also used. Arabic EL follows the syntactic features of English grammar as stated by the MLF rule in which ELs follow the grammatical rules of ML in the bilingual CP in which they appear. In Example 24, the Arabic NP (dars “lesson”) is preceded by English determiner “a”, which does not exist in Arabic and nevertheless follow English morphosyntactic principles in this bilingual CP, because English is the ML, the dominant language in this construction (see Example 24).

Example (24) Al: I have to write a dars then another dars.

I have to write a lesson then another lesson.

"I have to write a lesson then another lesson".

Moreover, the English definite article "the" is used in Example 25 as an ML system morpheme preceding the Arabic EL island "joma'a”; such form (Det "definite article" + NP) is also used in Arabic. The Arabic AdvP (ames "yesterday") is used in Example 26 as an EL island in a CP in which English is the ML which dominates the syntactic role in the whole bilingual CP (see Examples 25-26).

Example (25) Ba: On Friday we go to the joma'a.

On Friday we go to the mosque.

"On Friday we go to the mosque". 
Example (26) Ay: Ames we went outside to play.

Yesterday we went outside to play.

"Yesterday we went outside to play".

Most of Arabic islands the subjects used are names of foods and TV shows which apparently have no equivalent in English, or which their English counterparts are not known. For example, in Example 27, the child lists a number of dishes she likes, and since these are Libyan dishes, she used Arabic names for them by which these dishes are known at home. The rest of the morphemes are in English which is the ML as it plays the dominant role in this bilingual CP. The Arabic NP "bazeen" in Example 28 is the name of a Libyan dish that has no equivalent in English, so is the Arabic NP "sahleb" in Example 29. This can be considered "borrowing” more than "CS" (see Examples 27-29).

Example (27) Fa: I like ejja, roz and lahma and couscousy, mom always cooks them and we all love them.

I like omelet, rice and meat and couscous, mom always cooks them and we all love them.

"I like omelet, rice and meat and couscous, mom always cooks them and we all love them".

Example (28) Al: My favorite food is bazeen.

My favorite food is bazeen.

"My favorite food is bazeen".

Example (29) Fa: She likes to cook sahleb.

She likes to cook sahleb.

"She likes to cook sahleb".

It can be said that most of the ELs are in English, which reflects the dominance of English over Arabic in the speech of those young bilingual participants. In other words, the children tend to insert English ELs in their bilingual CPs more than they do with Arabic ELs. This indicates that the children are more competent in English than Arabic, and so English here can be considered the children's dominant language as it is the language in which they are most proficient (Mayers-Scotton, 2002, p. 62).

\section{Research Hypothesis Revisited}

The argument in this paper is based on the notion of classic CS, which is defined as CS "by speakers who have full proficiency in the participating language that becomes the Matrix Language and anywhere from limited to full proficiency in the other language” (Myers-Scotton, 2002, p. 25). This means that bilingual speakers do not have equal proficiency in the languages involved. We saw how the subjects in this research used a number of bare forms (ill-forms) in both Arabic and English; this means that subjects do not have sufficient mastery in the two languages as the premise of classic CS suggests. As Myers-Scotton (2002) stated, that the bilingual speaker "must be able to produce and recognize well-formed utterances in... one of the languages” (p. 25). Accordingly, in classic CS, bilingual speakers are assumed to have full mastery and perfect proficiency of the morphosyntax of one of the languages involved.

Data in this research show that the participants produce several English and Arabic bare forms which are ill-forms of EL; this means that the subjects are not fully proficient in either language especially when taking into consideration the fact that the subjects are children under 12 who are still going through the process of language development which is similar to that of monolingual language acquisition. Although it is well-known that Myers-Scotton is aware of this as a fact, it should have been provided in her explanation of the notion of 
classic CS. Furthermore, the participants produce more English ELs than Arabic ELs, which means that even though they are still developing their linguistic competence in the two languages and that the two languages do appear as ML in the participants' utterances, they are more acquainted with English than Arabic. Although English seems to be the dominant language which is used more frequently and proficiently than Arabic, it is not always the ML in the participants' bilingual utterances; utterances in which Arabic is the ML (the language that supplies the frame) are also produced. Despite the fact that Arabic is the ML in some utterances, children constantly use English phrases even in an Arabic utterance (English ELs).

\section{Conclusions}

Code switching is a conscious and systematic linguistic behavior in which certain grammatical structures are used in one language over the other(s) as that language becomes the most dominant one, the ML. One language can be an ML in some utterances, but this does not necessarily mean that it is always the ML in all utterances. However, one language can play as an ML in the speech of bilingual individuals in general, in that it is used more frequently in their bilingual utterances as ML, EL, and bare form constituents. This means that EL islands and bare forms of the most dominant language exist in the CPs of the least dominant one; however, the other way around is possible too, only less often.

The results also show how bilinguals do not need to have full mastery of a given language to use it as the ML; bare forms of that language can occur in the speech of bilinguals and yet it still acts as the dominant ML. In bilingual utterances of young bilinguals, one language may be more dominant than the other in some utterances; however, one language is generally more dominant than the other in the bilingual production as a whole. Likewise, one grammatical feature of one language can be inserted in a phrase in the other language, and this could be done frequently due to influence of one language over the other.

It thereby follows that CS models and principles though provide a detailed and generous explanation of the nature of CS theoretically; they cannot be generally applied to all kinds of CS as all contact phenomena differ cross-linguistically, cross-culturally, and even on the personal level among bilingual speakers. Moreover, CS theories generally focus on CS which occurs in specific situations such as that which exists in the utterances of immigrant families or bilingual communities. More research needs to be done regarding other CS situations which occur among bilingual speakers who do not belong to these bilingual environments.

\section{References}

Amuzu, E. (2005). Revisiting the classic codeswitching-composite codeswitching distinction: A case study of nonverbal prediction in Ewe-Englis codeswitching. Australian Journal of Linguistics, 25(1), 127-151.

Appel, R., \& Muysken, P. (1987). Language contact and bilingualism. London: Edward Arnold.

Auer, P. (2005). A postscript: Code-switching and social identity. Journal of Pragmatics, 37, 403-410.

Banerjee, R., \& Guiberson, M. (2012). Evaluation young children from culturally and linguistically diverse backgrounds for special education services. Young Exceptional Children, 15(1), 33-45.

Bentahila, A., \& Davies, E. (1983). The syntax of Arabic-French code-switching. Lingua, 59, 301-330.

Berk-Selgson, S. (1986). Linguistic constraints on intrasentential code-switching: A study of Spanish/Hebrew bilingualism (Vol. 15(3), pp. 313-348). Cambridge: Cambridge University Press.

Bokamba, E. (1988). Code-mixing, language variation, and linguistic theory: Evidence from Bantu languages. Lingua, 76, 21-62.

Boussofara-Omar, N. (2003). Revisiting Arabic diglossic switching in light of the MLF model and its sub-models: The 4-M model and the abstract level model. Bilingualism: Language and Cognition, 6(1), 33-46.

Brice, A., \& Anderson, R. (1999). Code mixing in a young bilingual child. Communication Disorders Quarterly, $21,17-22$.

Bullock, B., \& Toribio, J. (2010). The Cambridge handbook of linguistic code-switching. J Linguistics, 46, 488-493. 
Carnie, A. (2006). Syntax: A generative introduction. London: Blackwell Publishing Ltd..

CHUN, X. S. (2010). A study of Chinese-English code switching in Chinese sports news reports. Cross-Cultural Communication, 6(4), 165-175.

Cummins, J. (1979). Linguistic interdependence and the educational development of bilingual children. Review of Educational Research, 49(2), 222-251.

Fuller, J. (2000). Morpheme types in a matrix language turnover: The introduction of system morphemes from English into Pennsylvania German. International Journal of Bilingualism, 4(1), 45-58.

Gafaranga, J. (2005). Demythologising language alternation studies: Conversational structure vs. social structure in bilingual interaction. Journal of Pragmatics, 37, 281-300.

Garcia, E., \& Martinez, S. (1981). Bilingual development and the education of bilingual children during early childhood. Mexican American studies and research center: The University of Arizona.

Gonzalez-Vilbazo, K., \& Lopez, L. (2010). Some properties of light verbs in code-switching. Lingua, 121, 832-850.

Grosjean, F. (1982). Life with two languages: An introduction to bilingualism. Cambridge M.A.: Harvard University Press.

Guiberson, M. et al. (2006). Language maintenance and loss in preschool-age children of Mixican immigrants: Longitudinal study. Communication Disorders Quarterly, 28(1), 4-17.

Joshi, A. (1982). Processing of sentences with intra-sentential code-switching. In J. Horecky (Ed.), Coling 82 (pp. 145-150). Prague: North-Holland publishing company.

Joshi, A. (1985). Processing of sentences with intrasentential code switching. In D. R. Dowty, L. Karttunen, \& A. M. Zwicky (Eds.), Natural language parsing: Psychological, computational, and theoretical perspectives (pp. 190-205). Cambridge: Cambridge University Press.

Kassabgy, N. et al. (2004). Contrastive rhetorics. Cairo: The American University in Cairo Press.

Kim, L., \& Rezaeian, F. (2009). Code-switching in Persian/English and Korean/English conversations: With a focus on light verb constructions. The Linguistics Circle of The University of Victoria, 19, 232-244.

Kroll, J. F. (2008). Juggling two languages in one mind. Psychological Science Agenda, American Psychological Association, 22. Retrieved from http://www.apa.org/science/psa/kroll.html

Lowi, R. (2005). Bilinguals' creativity in the use of English in China’s advertising. In J. Cohen, K. T. McAlister, K. Rolstad, \& J. MacSwan (Eds.), Proceedings of the 4th international symposium on bilingualism (pp. 1393-1406). Somerville, M.A.: Cascadilla Press.

MacSwan, J. (2000). The architecture of the bilingual language faculty: Evidence from intrasentential code switching. Bilingualism: Language and Cognition, 3(1), 37-54.

Muller, N. (1998). Transfer in bilingual first language acquisition. Bilingualism: Language and Cognition, 1(3), 151-171.

Muto, T. (2010). The morphosyntax of Japanese/English code-switching: An optimality-theoretic approach. LSO Working Papers in Linguistics, 8, 54-70.

Myers-Scottn, C. (2005). Uniform structure: Looking beyond the surface in explaining codeswitching. Rivista Di Linguistica, 17(1), 15-34.

Myers-Scotton, C. (1993). Common and uncommon ground: Social and structural factors in codeswitching. Language in Society, 22, 475-503.

Myers-Scotton, C. (2002). Contact linguistics: Bilingual encounters and grammatical outcomes. Oxford: Oxford University Press.

Myers-Scotton, C. (2006a). Multiple voices: An introduction to bilingualism. Oxford: Blackwell.

Myers-Scotton, C. (2006b). Natural codeswitching knocks on the laboratory door. Bilingualism: Language and Cognition, 9(2), 203-212.

Myers-Scotton, C. (2008). Language contact: Why outsider system morphemes resist transfer. Journal of Language Contact, 2 , 21-41.

Myers-Scotton, C., \& Jake, J. (1995). Matching lemmas in a bilingual language competence and production: Evidence from intrasentential code switching. Linguistics, 33, 981-1024.

Paradis, J., Nicoladis, E., \& Genesee, F. (2000). Early emergence of structural constraints on code-mixing: Evidence from French-English bilingual children. Bilingualism: Language and Cognition, 3(3), 245-261.

Pert, S., \& Letts, C. (2006). Codeswitching in Mirpuri speaking Pakistani heritage preschool children: Bilingual language acquisition. International Journal of Bilingualism, 10(3), 349-374.

Pfaff, C. (1979). Constraints on language mixing: Intrasentential code-switching and borrowing in Spanish/English. Linguistic Society of America, 55(2), 291-318. 
Poplack, S. (1980). Sometimes I'll start a sentence in Spanish: Towards a typology of code—Switching. Linguistics, 18, 581-618.

Redouane, R. (2005). Linguistic constraints on codeswitching and codemixing of bilingual Moroccan Arabic-French speakers in Canada. In J. Cohen, K. T. McAlister, K. Rolstad, \& J. MacSwan (Eds.), Proceedings of the 4th international symposium on bilingualism (pp. 1921-1933). Somerville, M.A.: Cascadilla Press.

Schiff-Myers, N. (1992). Considering arrested language development and language loss in the assessment of second language learners. American Speech-Language-Hearing Association, 23, 28-33.

Schmitt, E. (2000). Overt and covert codeswitching in immigrant children from Russia. International Journal of Bilingualism, 4(1), 9-28.

Toribio, A. (2001). On the emergence of bilingual code-switching competence. Bilingualism: Language and Cognition, 4(3), 203-231.

WEI, L., \& Milroy, L. (1995). Conversational code-switching in a Chinese community in Britain: A sequential analysis. Journal of Pragmatics, 23, 281-299. 